\title{
Analysis of the process model of airport: creating the high level process map
}

\author{
Natalia Buldakova \\ Department of Air Transport \\ Faculty of Transportation Sciences, Czech Technical \\ University \\ Horská 3, Praha 2, 128 03, Czech Republic \\ e-mail: buldanat@fd.cvut.cz
}

\author{
Denisa Dociová \\ Department of Air Transport \\ Faculty of Transportation Sciences, Czech Technical \\ University \\ Horská 3, Praha 2, 128 03, Czech Republic \\ e-mail: docioden@fd.cvut.cz
}

\author{
Peter Vittek \\ Department of Air Transport \\ Faculty of Transportation Sciences, Czech Technical University \\ Horská 3, Praha 2, 128 03, Czech Republic \\ e-mail: xvittek@fd.cvut.cz
}

\begin{abstract}
This article describe the analysis of the process models of airport, which are described in Ground Operation Manual. The main goal is creating high level process map.
\end{abstract}

Keywords - airport processes, safety, process maps, safety management system.

\section{INTRODUCTION}

Increasing competition and pressure on reduction of costs led to concern over the level of safety provided by airline companies. These concerns are reinforced by information obtained during the investigation of the causes of aviation incident, which indicate the growing influence of the internal culture and decision-making processes of organizations involved in civil aviation safety. In this connection, it is important to understand the processes occurring in these organizations and the risks arising in the course of their application. Currently, a majority of the processes is described in Ground Operation Manual (GOM), but the manual is not clear and easy to understand. The required visibility subsequently give graphs, or in our case, process maps. They allow tracking arising risks from a high to a low level.

\section{THE PURPOSE OF CREATION OF PROCESS MAPS AND ANALYSIS OF PROCESSES IN AIRPORT.}

Ground Operation Manual (GOM) is a guide by which all procedures are carried out at the airport. These processes are described in text form, they are tangled and do not allow us to follow the relationship between the elements of the system. In this regard, very often employees do not fully acquaint themselves with all information in the manual. Besides this GOM is quite bulky and inconvenient for amending it.
The solution to all of the above issues is to make process maps of the Airport.

High level process map allows us to represent the airport in the form of a complex system, in which each individual elements (processes and participants) interact and influence each other.

Process maps are based on the actual situation in the enterprise, they are created with the participation of senior staff and specialists and employees. They should include all processes of the airport from the highest to the lowest levels.

The process modeling allows to establish the risks that may arise in the processes of the organization. We can determine these risks as a result of comparison of the described processes (based on observation of actions realized in reality) and guidance documentation and current regulations, which determine the rules for the process. The result of evaluation may include the following risks:

- discrepancy guidance documentation of airport and established norms;

- inobservance of the rules by workers;

- insufficiently formulated documentation (too hard for understanding by employees), etc.

After determination of these risks we may create appropriate security measures.

\section{TOOLS FOR ANALYSIS AND SELECTION OF A SUITABLE METHODOLOGY}

During creating the process maps currently mainly used the three following methods - UML, BPMN, ARIS. We consider the advantages and disadvantages of these methods and choose the most suitable for us. 
BPMN methodology (Business Process Model and Notation) has been standardized by OMG group in 2006, current version was introduced in January 2011. The main goal of BPMN is the creation of a standard set of symbols which are understandable to all business users, such as business analysts who create and improve processes, technical developers responsible for implementing the processes and managers who take care of processes and managing them. Consequently, BPMN is intended to serve as a link between the design phase of the business process and the phase of its implementation.

BPMN supports only a set of conceptions necessary for modeling business processes. Modeling of other aspects, except business processes, is out of focus BPMN. For example, the modeling of some aspects is not described in BPMN, such as data model, organizational structure.

Despite that BPMN allows modeling data flows and message flows, as well as associate data with the actions, it is not a diagram of information flows. This methodology is not suitable to compile our process map, because the organizational structure of the company is an important element for us.

ARIS methodology (Architecture of Integrated Information Systems) - is a software for modeling business processes of organizations. The owner of product and methodology is German company Software AG. The developer of this product is the German company IDS Prof. Scheer, who is a world leader in the development of tools for the analysis and restructuring of business processes, as well as well-known in the world as a consulting firm engaged in the reorganization of the business.

The ARIS methodology is a powerful tool for the analysis and development of solutions. It allows to optimize organizational activity and structure of the enterprise, is applicable to:

- description and managing the organizational structure of the enterprise;

- modeling and analysis of business processes of the organization

- $\quad$ reporting of the constructed models.

Within each of these activities create models of different kinds, reflecting the relevant sides of the observable system. ARIS supports a wide range of modeling methods used to construct of these models. Among them are such well-known as Unified Modeling Language (UML), Object Modeling Technique (OMT), etc. The latest version ARIS supports more than 83 modeling methods.

For this project, the ARIS system is too cumbersome and complicated, we can use a more simplified approach. Furthermore ARIS is considerably more expensive system than others.

UML (Unified Modeling Language) — is a graphical description language for object modeling in the field of software development. UML is a general-purpose modeling language, which is designed to provide a standard way to

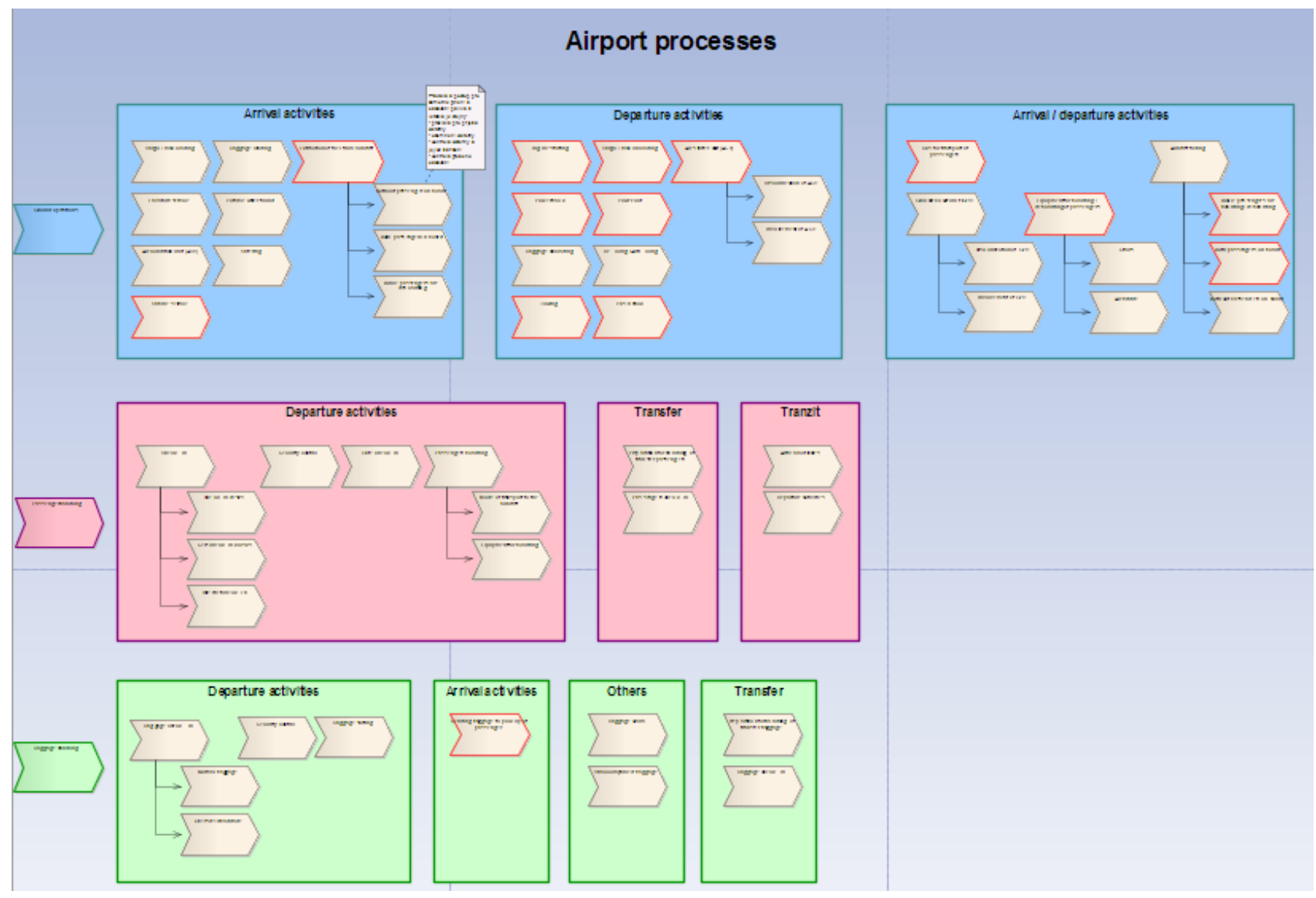

Figure 1. High level process map of airport 
visualize the design of a system, called the UML model. UML was created to define, visualize, design and documentation of software systems.

The use of UML is not restricted to modeling software. It is also used for business process modeling, system design and display of organizational structures.

UML allows to describe the system with almost all possible angles and different aspects of the system. UML diagrams are relatively easy to read after a fairly quick overview of its syntax. This language is continually evolving and is used in other programs as a component, such as ARIS.

Thereby, for our project the most suitable is UML diagrams, they allow to describe in detail all processes taking place at the airport with the company's organizational structure, visualize them in an easy to read format.

\section{CREATING HIGH LEVEL PROCESS MAP.}

UML-diagrams could help us in analysis of the process maps and create high level process map.

UML language consists of three elements. These elements are used to create two-dimensional graphs - the results of the modeling tool:

- objects;

- relationships;

- diagrams.

There are 13 official diagrams UML 2.0, each of which represents a different view of the different aspects of the system: class diagram, component diagram, composite structure diagram, deployment diagram, object diagram, package diagram, activity diagram, state machine diagram, use case diagram, communication diagram, sequence diagram, interaction overview diagram, timing diagram. Since we create process map of the airport and we work with GOM, then we are interested in an activity diagram.

Activity diagram is a diagram showing the decomposition of some activity on its constituent parts. Under the term activity we understand specification of executable behavior in the form of coordinated sequential and parallel execution subordinate elements.

As part of the process modeling, we used, primarily, diagrams to create a process map at level of strategic control (high level process map - figure 1). From this viewpoint, we presented the structure of handling processes occurring at the airport.

We divided all the processes into groups technical handling (ground operation) and commercial handling (passengers and baggage handling). Further we divided separate groups into subgroups, such as arriving activities of technical handling, departing activities of technical handling and actions that may be performed inside of within departing and arriving activities.
Processes can be considered as independent simple actions, which will be described in a separate process model with opportunity to communicate with other processes, or they can be characterized as a "super processes" which include other processes.

For example, consider the process of commercial handling. We can divide it into "departing passengers", "transit passengers" then, within each group we create a "super process" that includes the overall processes of the passengers check-in and the baggage handling, which are kept in groups (Figure 2).

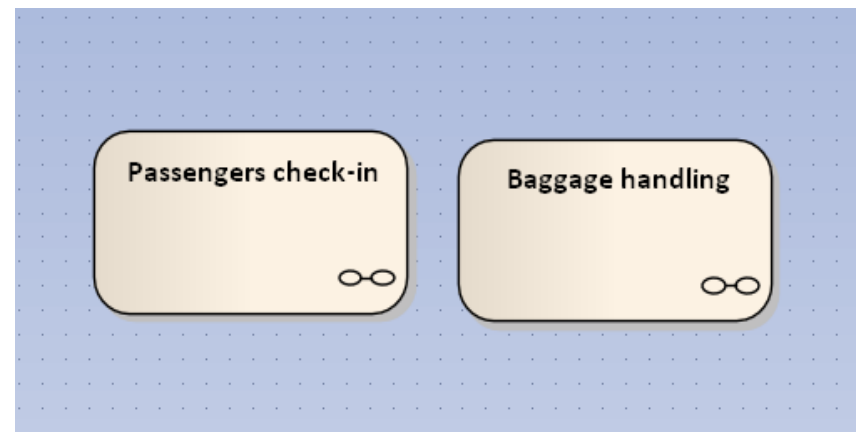

Figure 2. Commercial handling

Further, each of these processes separately is presented as an activity diagram that describes in detail all actions taking place within the framework of this process and its participants.

As an example, we take the baggage handling (Figure 4). This process consist in the following actions: Placing baggage on the first conveyor belt $\rightarrow$ Weighting of baggage $\rightarrow$ Registration in baggage handling system $\rightarrow$ Labeling of baggage by baggage tag. Object decision follows further. In that object takes place decision making at the level of YES / NO question, in our case it is standard luggage (Figure 3). If yes, then action continues $\rightarrow$ Sending baggage on the second conveyor belt $\rightarrow$ Sending to baggage sorting. If no, then $\rightarrow$ Transportation to oversized baggage desk $\rightarrow$ Security check $\rightarrow$ Sending to baggage sorting.

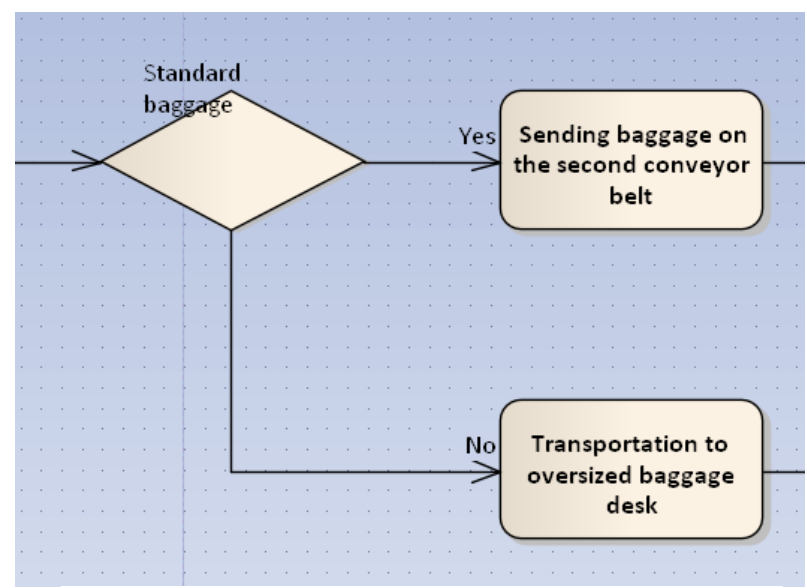

Figure 3. Decision activity 


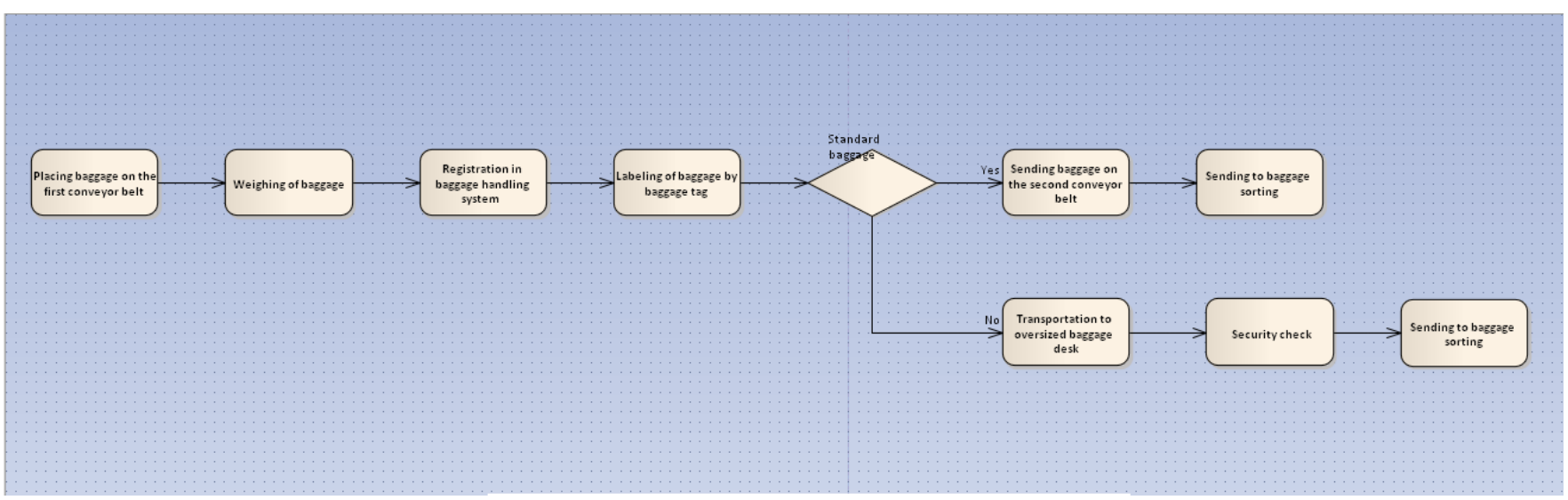

Figure 4. Baggage handling

Thus, this diagram allows us to follow the process with all the actions taking place within it from start to finish with specification of the participants and sub processes.

\section{CONCLUSION}

Currently, the issue of safety is the most important in the development of air transport. Safety is increasingly seen as the control of risk factors. Because of that the Safety Management Manual specify the Safety as: "Safety is a condition in which the risk of harm to persons or damage to property is reduced to an acceptable level and maintained at a lower level through a continuous process of hazard identification and risk management [5]".

High level process map gives us a look at the airport as a complex system in which continuously interact different objects, in addition it gives us the opportunity to follow the possibility of potential risks and take precautions. Furthermore, this diagrams gives employees the opportunity to familiarize them with processes taking place at the airport in a more visible manner and to work with GOM in easy form.

\section{ACKNOWLEDGEMENT}

This paper was supported by the grant agency of the Czech Technical University in Prague, grant No. SGS14/164/OHK2/2T/16.

\section{REFERENCES}

[1] Процессный подход // Серия «Все о качестве. Зарубежный опыт». НTК «Трек», 2000.

[2] Хаммер М., Хершман Л.: Быстрее, лучше, дешевле. Девять методов реинжиниринга бизнес-процессов. Альпина Паблишер, 2012.

[3] Unified Modeling Language - ofitial web-site Available at: http://www.uml.org/

[4] All figures are made in Enterprise architecture — ofitial web-site Available at:

http://www.sparxsystems.com.au/

[5] Safety Management Manual (SMM), Doc 9859, AN/474, Third Edition, ICAO - 2013 